\title{
US extends security clearance for scholars
}

\section{Geoff Brumfiel, Washington}

The US government has announced that visa-related security checks will remain valid for up to four years. The planned change will ease travel in and out of the country, and greatly reduce the chance that students or scientists are left stranded abroad.

Academic groups are delighted with the move, which they say will simplify visitors' trips home. "It's fantastic," says Wendy White, head of the international office at the National Academy of Sciences in Washington. "I think it will make a big difference for visiting students and scholars."

The Department of State and the Department of Homeland Security, which are jointly responsible for immigration policy, revealed their decision on 11 February. "This change sends a clear message that the United States encourages those with great scientific minds to explore studying and working in our country," said a statement from Asa Hutchinson, under-secretary for borders and transportation at the homeland security department.

Since the terrorist attacks of 11 September 2001, background checks have been

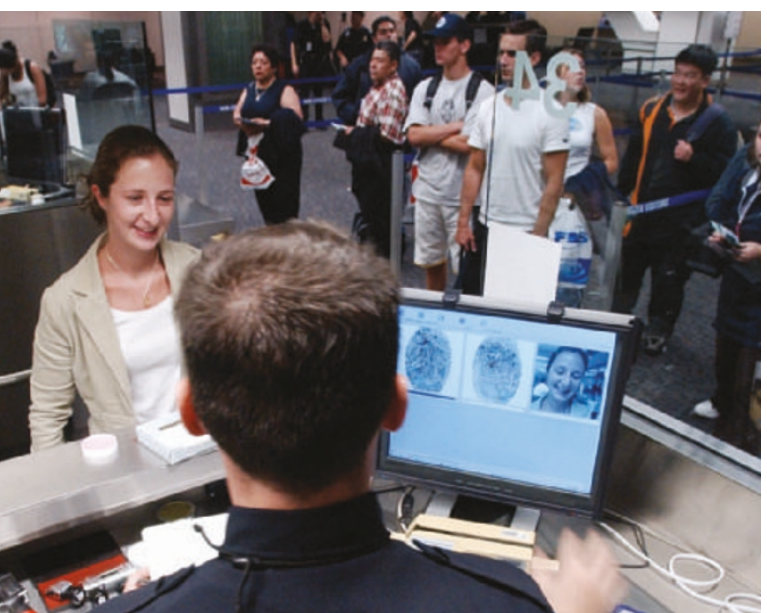

Hail fellow: visa problems have dogged scientists visiting the United States.

visiting the country for conferences and other events will hold valid security clearance for 12 months. The net effect is that researchers will be able to move in and out of the United States more easily after an initial check has been done, according to Angela Aggeler, a spokeswoman for the state department.

Aggeler adds that the average time taken to make a security check has already been slashed from 75 to 14 days over the past year. "We will continue to try and lower the waiting time," she says.

"I think that this kind of

required for many scientists seeking visas to work or study in the United States. In the past, the checks have led to lengthy delays that caused some researchers to miss meetings or the start of academic years. Even students who had studied in the United States for years found themselves unable to return until their security checks had been completed (see Nature 427, 190-195;2004).

Under the new scheme, security clearances for students will be valid for four years, and those for scientists working in the United States on scholar or work visas will last for two years. In addition, researchers change sends a good signal to the international community," says Heath Brown, director of research and policy analysis at the Council of Graduate Schools in Washington. A survey by the council last year showed that the number of foreign students admitted to US schools was down in 2004 (see Nature $431,231 ; 2004)$. Brown says that he hopes the changes will bring foreign students and scholars back to US universities, but he points out that many still see the country as an unwelcoming place in the wake of 9/11. White agrees: "We have to get the word out that things really are better."

\section{Nuclear-physics research falls foul of budget cuts}

Jessica Ebert, Washington

US physicists are hitting out hard at the Bush administration's budget proposal for next year. They claim that the plan, which would cut overall spending on research in physics by about $4 \%$, will imperil the country's global leadership in the discipline.

"If these cuts stand," says Tom Ludlam, a physicist at Brookhaven National Laboratory in New York state, "there will be a significant reduction in the number of $\mathrm{PhD}$ scientists, graduate students, postdocs and senior scientists doing physics here in America."

The Department of Energy's Office of Science, which funds most US physics research, formulated a plan in November 2003 to construct or upgrade 28 different facilities over the next 20 years. Physicists say that the proposed budget will prevent the plan from being implemented.

If approved by Congress, the budget request would support some of the facilities, including construction of the Linac Coherent Light Source at the Stanford Linear Accelerator Center in California. But it would cancel or delay several other projects that the plan identified as priorities.

For instance, the budget would cancel the $\mathrm{BTeV}$ experiment, which aims to use the Tevatron collider at Fermilab, Chicago, to investigate the imbalance between matter and antimatter in the Universe. The experiment received a top ranking in the 2003 plan. "This is quite a blow to us," says project director Joel Butler. "Everything was in place," he adds. "We were more than ready to go."

The science-office budget has been essentially flat since 2001, but Raymond Orbach, head of the energy department's science office, defends the 2006 proposal. "I'm very happy with the structure of the budget," he says. "It enables us to maintain scientific leadership on a global scale."

Martha Krebs, a consultant in Los Angeles who ran the science office under Bill Clinton, says the budget reveals the areas in which the Bush administration wants to "be a leader". She says that nuclear physics, in particular, does not seem to be one of these.
The 2006 nuclear-physics request for US\$371 million is $8 \%$ less than this year's budget. Brookhaven and the Thomas Jefferson National Accelerator Facility in Newport News, Virginia, would bear the brunt of the cut. At the Jefferson lab, a plan to double the energy of the laboratory's continuous electron beam - also ranked highly in the 2003 plan - would be deferred. In addition, the electron beam's operating hours would be cut by almost one-third.

At Brookhaven, the cut would decrease operating hours at the Relativistic Heavy Ion Collider - the laboratory's main nuclearphysics facility - by almost two-thirds. "It's not a good situation," says Rick Casten, a physicist at Yale University and chairman of the Nuclear Science Advisory Committee. "We're going to lose our competitiveness if this keeps up and is not reversed."

For more news and analysis go to news@nature.com www.nature.com/news 